\title{
Modelling the Dissolution/Precipitation of Ideal Solid Solutions
}

\author{
E. Nourtier-Mazauric ${ }^{1 *}$, B. Guy², B. Fritz ${ }^{3}$, E. Brosse ${ }^{4}$, D. Garcia ${ }^{2}$ and A. Clément ${ }^{3}$ \\ 1 École nationale supérieure des mines de Saint-Etienne - 152 cours Fauriel, 42023 Saint-Etienne Cedex - France \\ 2 idem - affiliated to U.R.A. C.N.R.S. no. 6524 \\ 3 Centre de géochimie de la surface, C.N.R.S. - 1 rue Blessig, 67084 Strasbourg Cedex - France \\ 4 Institut français du pétrole - 1 et 4 avenue de Bois-Préau, 92852 Rueil-Malmaison Cedex - France \\ e-mail: elise_nourtier@yahoo.fr - guy@emse.fr - bfritz@illite.u-strasbg.fr - etienne.brosse@ifp.fr - \\ garcia@emse.fr - aclement@illite.u-strasbg.fr \\ *Corresponding author
}

\begin{abstract}
Résumé - Modélisation de la dissolution/précipitation des solutions solides idéales - Le comportement cinétique d'une solution solide idéale est modélisé en mettant en compétition deux réactions : la dissolution stoechiométrique du solide existant et la précipitation du composé le moins soluble, c'està-dire celui par rapport auquel la sursaturation du fluide est maximum ; les vitesses de ces deux réactions sont exprimées en fonction des écarts à l'équilibre correspondants, les constantes cinétiques dépendant du $\mathrm{pH}$. Dans ce modèle idéal, les courbes de saturation et l'évolution du fluide au sein d'un système réactif simple peuvent être représentées commodément dans des diagrammes en potentiels chimiques. La simulation d'un système géochimique, constitué d'un aquifère gréseux glauconieux parcouru par une eau de mer enrichie en carbonates, permet d'analyser l'impact de la prise en compte de deux solutions solides ferro-magnésiennes, une calcite et une chlorite, sur les échanges Fe-Mg, au cours de la dissolution des carbonates. Le modèle rend bien compte de la tendance des solutions solides à se dissoudre de façon congruente avant que la précipitation ne commence et ne ramène le fluide vers l'équilibre.
\end{abstract}

\begin{abstract}
Modelling the dissolution/precipitation of ideal solid solutions - The kinetic behaviour of an ideal solid solution is modelled by two competing reactions: the stoichiometric dissolution of the existing solid and the precipitation of the least soluble compound, i.e. that with respect to which the oversaturation of the fluid is maximum; both reaction rates are expressed as a function of the corresponding departure from equilibrium, with a $\mathrm{pH}$-dependent kinetic constant. Within this ideal model, the saturation curves and the fluid evolution of a simple reacting system may be displayed conveniently in chemical potential diagrams. The simulation of a geochemical system, constituted of a glauconitic sandstone aquifer infiltrated through by a sea water enriched in carbonates, allows to analyze the impact of taking into account two ferro-magnesian solid solutions, a calcite and a chlorite, on Fe-Mg exchanges during carbonates dissolution. The model accounts well for the tendency of solid solutions to dissolve congruently before precipitation starts and drives the fluid composition towards equilibrium.
\end{abstract}




\section{INTRODUCTION}

The kinetic behaviour of multiphasic solid-fluid assemblages is usually described by competing mineral dissolutions and precipitations, and is governed by departure from equilibrium.

When a solid solution is considered instead of minerals of fixed composition, theoretical and practical complications arise:

1. departure from equilibrium is written differently depending on whether the composition of the solid solution is invariant or not, i.e. whether the stoichiometric saturation of the existing solid solution (Thorstenson and Plummer, 1977) or the total saturation of the whole range of potential compounds pertaining to the solid solution (Denis and Michard, 1983; Michard, 1986) is considered;

2. in general, equilibrium cannot be reached only by dissolving or precipitating the existing solid solution, and coprecipitation must be added to stoichiometric dissolution; when the aqueous solution is oversaturated with respect to a particular range of minerals pertaining to the solid solution, precipitation proceeds with a composition which is a priori different from that of the existing solid solution, and a rule must be introduced to calculate this composition as well as the reaction rate.

Transformations of solid solutions, whether ideal or nonideal, in solid solution-aqueous solution systems, have been studied, whether theoretically or experimentally, by many authors (Thorstenson and Plummer, 1977; Lippmann, 1977, 1980; Michard, 1989; Glynn, 1990; Glynn and Reardon, 1990; Blanc, 1996; Blanc et al., 1997; Pina et al., 2000; among others). This study aims to discuss especially kinetic aspects of the pre-cited problems (points 1 and 2) for ideal solid solutions, in a theoretical way.

This paper is organized as follows. In section 1, a few notions about equilibria of solid solutions are shortly summarized and illustrated on chemical potential diagrams. In section 2, the model used to describe the reactions between solid solutions and an aqueous solution is presented. In section 3, a reactive transport computer code, named DIAPHORE SOLSOL (Nourtier-Mazauric, 2003), is described. It takes into account the behaviour of ideal solid solutions as well as fixed compounds. In the last section, a simulation is conducted with this code in the context of $\mathrm{CO}_{2}$ sequestration. Diaphore SolSol is used to study the injection of sea water enriched in carbon, in a glauconitic sandstone aquifer containing a carbonate solid solution and a silicate one among other minerals.

\section{NOTATIONS}

Roman symbols are constants, italic symbols are variables.

$a_{i} \quad$ activity of the $i$ th aqueous species [dimensionless] $c_{l} \quad$ total concentration of the $l$ th element [number of moles per mass of solvent]

$i \quad$ subscript denoting an aqueous (basis or secondary) species

I ionic strength calculated using molalities (moles/kg $\mathrm{H}_{2} \mathrm{O}$ )

$j \quad$ subscript denoting an aqueous secondary species

$k \quad$ subscript denoting an aqueous basis species

$k_{\mathrm{d}_{m}} \quad$ kinetic dissolution constant of the $m$ th mineral [number of moles per unit of surface and unit of time]

$k_{\mathrm{p}_{m}} \quad$ kinetic precipitation constant of the $m$ th mineral [number of moles per unit of surface and unit of time]

$K_{j} \quad$ solubility product of the $j$ th secondary species [dimensionless]

$l \quad$ subscript denoting a chemical element

$m$ subscript denoting a mineral (pure one or solid solution)

$m_{i} \quad$ molality of the $i$ th aqueous species [number of moles per mass of solvent]

$\mathrm{M}_{m} \quad m$ th mineral (pure one or solid solution)

$\mathrm{N}_{\mathrm{a}} \quad$ number of aqueous species: $\mathrm{N}_{\mathrm{a}}=\mathrm{N}_{\mathrm{c}}+\mathrm{N}_{\mathrm{x}}$

$\mathrm{N}_{\mathrm{c}} \quad$ number of aqueous basis species

$\mathrm{N}_{\mathrm{em}}(s)$ number of end-members in the sth solid solution

$\mathrm{N}_{\mathrm{m}} \quad$ number of mineral species

$\mathrm{N}_{\mathrm{x}} \quad$ number of aqueous secondary species

$p \quad$ subscript denoting a pure mineral

$\mathrm{R} \quad$ gas constant: $\mathrm{R}=8.314 \mathrm{~J} \cdot \mathrm{mol}^{-1} \cdot \mathrm{K}^{-1}$

$s \quad$ subscript denoting a solid solution

$s_{m} \quad$ reactive surface area of the $m$ th mineral [surface per volume of solution]

$S_{m} \quad$ geometric surface area of the $m$ th mineral [surface per volume of solution]

$\mathrm{S}_{k} \quad k$ th aqueous basis species

$\mathrm{S}_{j} \quad j$ th aqueous secondary species

$T$ temperature

$\vartheta_{m} \quad$ kinetic reaction rate of the $m$ th mineral by solution volume unit [number of moles per volume of solution per unit of time]

$V_{m} \quad$ molar volume of the $m$ th mineral

$X_{\iota_{s}} \quad$ mole fraction of the $\iota$ th end-member component in the sth solid solution [dimensionless]

$\overline{X_{\iota_{s}}} \quad$ mole fraction of the $\iota$ th end-member component in the sth solid solution of fixed composition [dimensionless]

$\widetilde{X_{\iota_{s}}} \quad$ mole fraction of the $\iota$ th end-member of the least soluble solid solution of type $s$ [dimensionless]

$\alpha_{l i} \quad$ number of moles of the $l$ th element in one mole of the $i$ th aqueous species

$\beta_{l m} \quad$ number of moles of the $l$ th element in one mole of the $m$ th mineral

$\iota_{s} \quad$ subscript denoting an end-member component of the $s$ th solid solution 
$\Delta_{r} G_{l_{s}} \quad$ Gibbs free energy of reaction of the $\iota$ th end-member of the sth solid solution [energy per number of moles]

$\Gamma_{m} \quad$ critical oversaturation threshold of the $m$ th mineral [dimensionless]

$\phi_{m} \quad$ volume fraction of the $m$ th mineral in the medium (water + rock) [dimensionless]

$\Phi \quad$ porosity [dimensionless]

$v_{j k} \quad$ stoichiometric coefficient of the $k$ th aqueous basis species in the dissociation reaction of the $j$ th aqueous secondary species

$v_{m k} \quad$ stoichiometric coefficient of the $k$ th aqueous basis species in the dissociation reaction of the $m$ th mineral

$\Omega_{l_{s}} \quad$ saturation degree of the pure phase corresponding to the $\iota_{s}$ th end-member component [dimensionless]

$\Omega_{\mathrm{S}_{s\left(\overline{X_{s}}\right)}}$ stoichiometric saturation degree of the sth solid solution of fixed composition $\left(\overline{X_{\iota_{s}}}\right)_{\iota_{s}=1, \ldots, \mathrm{N}_{\mathrm{em}}(s)}$ [dimensionless]

$\Omega_{\mathrm{T}_{s}} \quad$ total saturation degree of the sth solid solution [dimensionless]

\section{THEORETICAL BACKGROUND AND CHEMICAL POTENTIAL DIAGRAMS}

A solid solution is described by a decomposition into endmembers. Its composition then varies with its end-member mole fractions. For example, a carbonate solid solution $\mathrm{Ca}(\mathrm{Fe}, \mathrm{Mg})\left(\mathrm{CO}_{3}\right)_{2}$ is represented by 2 end-members, pure ankerite $\mathrm{CaFe}\left(\mathrm{CO}_{3}\right)_{2}$ and pure dolomite $\mathrm{CaMg}\left(\mathrm{CO}_{3}\right)_{2}$.

At a given time, the solid solution may be present in a geochemical system with a determined composition. This mineral phase of specific chemical composition, which will be referred to as the particular solid solution, is distinct from the set defined by the solid solution end-members, which will be designated as the generic solid solution. The particular solid solution is produced as an "instant composition" of the generic solid solution. For instance, $\mathrm{Ca}\left(\mathrm{Fe}_{0.6} \mathrm{Mg}_{0.4}\right)\left(\mathrm{CO}_{3}\right)_{2}$ is a particular solid solution of the $\mathrm{Ca}(\mathrm{Fe}, \mathrm{Mg})\left(\mathrm{CO}_{3}\right)_{2}$ generic solid solution.

\subsection{Thermodynamic equilibrium}

When the solid solution is ideal, the activity of each endmember is equal to its mole fraction.

The equilibrium condition between an ideal solid solution and an aqueous solution is thus expressed as the following partial mass action laws:

$$
\Omega_{\iota_{s}}=X_{\iota_{s}}, \forall \iota_{s} \in\left[1, \mathrm{~N}_{\mathrm{em}}(s)\right]
$$

(Garrels and Christ, 1965), where $X_{\iota_{s}}$ is the end-member mole fraction and $\Omega_{\iota_{s}}$ the saturation degree of the pure phase corresponding to each end-member. This saturation degree

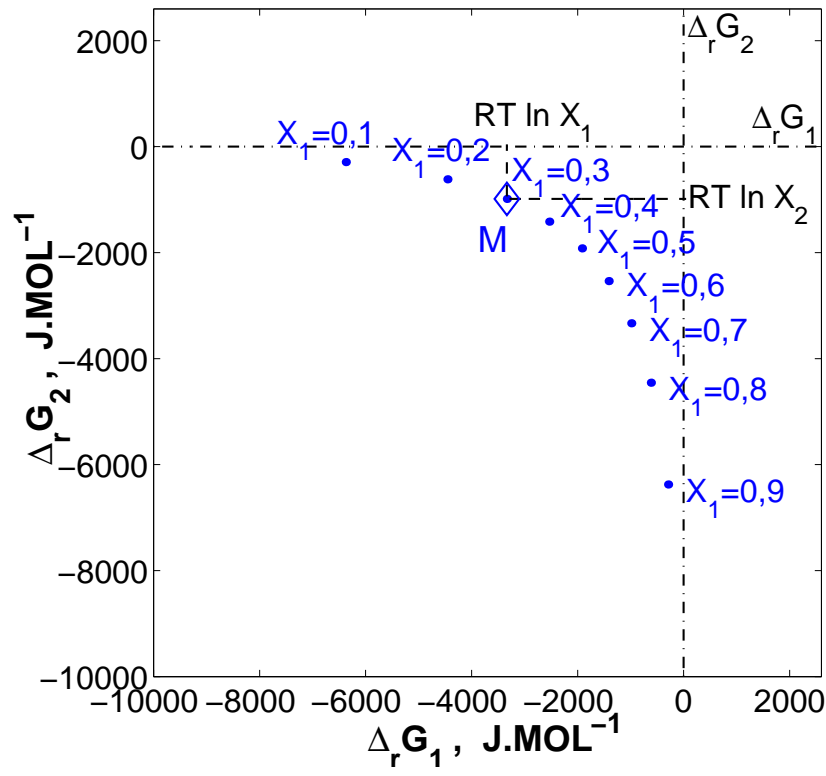

Figure 1

Various aqueous solutions at thermodynamic equilibrium with a binary ideal solid solution $\left(\mathrm{P}_{1}, \mathrm{P}_{2}\right)$ whose composition is given by its end-member mole fractions $\left(\mathrm{X}_{1}, \mathrm{X}_{2}\right)$.

is the ratio of the ionic activity product and the equilibrium constant of the dissociation reaction of the end-member in the aqueous solution.

The partial mass action laws (1) can be illustrated in chemical potential diagrams (Guy, 2003; Nourtier-Mazauric, 2003). More precisely, the geochemical system is represented by a point whose coordinates are the $\mathrm{N}_{\mathrm{em}}(s)$ overall Gibbs free energies of dissociation of the solid solution endmembers in the aqueous solution. For a binary solid solution, these overall Gibbs free energies are defined as

$$
\left\{\begin{array}{l}
\Delta_{r} G_{1}=\mathrm{R} T \ln \Omega_{1}, \\
\Delta_{r} G_{2}=\mathrm{R} T \ln \Omega_{2} .
\end{array}\right.
$$

In the case of an aqueous solution at thermodynamic equilibrium with an ideal binary solid solution $\mathrm{M}_{s}$, the overall Gibbs free energies of dissociation of $\mathbf{M}_{s}$ end-members in the aqueous solution are thus given by

$$
\left\{\begin{array}{l}
\Delta_{r} G_{1}=\mathrm{R} T \ln X_{1}, \\
\Delta_{r} G_{2}=\mathrm{R} T \ln X_{2}=\mathrm{R} T \ln \left(1-X_{1}\right) .
\end{array}\right.
$$

Therefore, fluids at thermodynamic equilibrium with particular binary ideal solid solutions of known composition $\left(X_{1}=0.1,0.2,0.3, \ldots, 0.9\right)$ are represented on chemical potential diagrams by points $\left(\mathrm{R} T \ln X_{1}, \mathrm{R} T \ln \left(1-X_{1}\right)\right)^{(1)}$ (figure 1).

(1) In this paper, all chemical potential diagrams are drawn for a temperature of $333 \mathrm{~K}$, identical to the one of the application (see section 4). 
By language abuse, these points will be referred to either as aqueous solutions or as particular solid solutions of various compositions (at thermodynamic equilibrium). For instance, the binary ideal solid solution of composition $\left(X_{1}=0.3\right.$, $X_{2}=0.7$ ) is represented by point $\mathrm{M}$ on figures 1 to 6 .

In this paper, chemical potential diagrams have been preferred to other types of diagrams such as those introduced by Lippmann $(1980,1982)$ to depict solid and aqueous compositions at equilibrium. The latter could have been developed without modifying our modelling approach. Among some interests for this study, chemical potential diagrams allow to define the scope of particular solid solutions with respect to which the fluid is oversaturated (see section 2.2, especially figures 5 and 6), to visualize chemical reaction affinities ${ }^{(2)}$ and to depict evolution of fluids which are out of equilibrium (see section 4).

\subsection{Stoichiometric saturation}

If the solid solution reacts in an aqueous phase without changing composition (e.g. owing to kinetic restrictions), its equilibrium with the fluid is referred to as stoichiometric saturation (Thorstenson and Plummer, 1977; Glynn and Reardon, 1990).

The mass action law of the reaction between the aqueous solution and this solid solution, whose end-member mole fractions $\left(\overline{X_{\iota_{s}}}\right)_{\iota_{s}=1, \ldots, \mathrm{N}_{\mathrm{em}}(s)}$ are fixed, is

$$
\Omega_{\mathrm{S}_{s\left(\overline{X_{\iota s}}\right)}}=1
$$

where the stoichiometric saturation degree $\Omega_{\mathrm{S}_{s\left(\overline{X_{s}}\right)}}$ of the aqueous solution with respect to the solid solution of fixed composition $\left(\overline{X_{\iota_{s}}}\right)$ is defined as (Tardy and Fritz, 1981)

$$
\Omega_{\mathrm{S}_{s\left(\overline{X_{\iota s}}\right)}}=\prod_{\iota_{\iota_{s}}=1}^{\mathrm{N}_{\mathrm{em}}(s)}\left(\frac{\Omega_{\iota_{s}}}{\overline{X_{\iota_{s}}}}\right)^{\overline{X_{\iota_{s}}}} .
$$

In a chemical potential diagram, any aqueous solution at stoichiometric saturation with a binary ideal solid solution of fixed composition $\left(\overline{X_{1}}, \overline{X_{2}}\right)$, represented by a point $\mathrm{M}$ of coordinates $\left(\mathrm{R} T \ln \overline{X_{1}}, \mathrm{R} T \ln \overline{X_{2}}\right)$, follows a straight line $\left(\mathrm{S}_{\mathrm{S}(\mathrm{M})}\right)$ passing by the point $\mathrm{M}$ (figure 2 ). Various fixed compositions of the ideal solid solution $\left(\overline{X_{1}}=0.1,0.2,0.3, \ldots, 0.9\right)$ thus lead to various stoichiometric straight lines.

\subsection{Total saturation}

Denis and Michard (1983) introduced the notion of total saturation in order to state a sole thermodynamic equilibrium condition between an aqueous phase and an ideal

(2) On chemical potential diagrams, disequilibrium extent can be evaluated by considering the distance between the point which represents the aqueous solution and the total saturation curve.

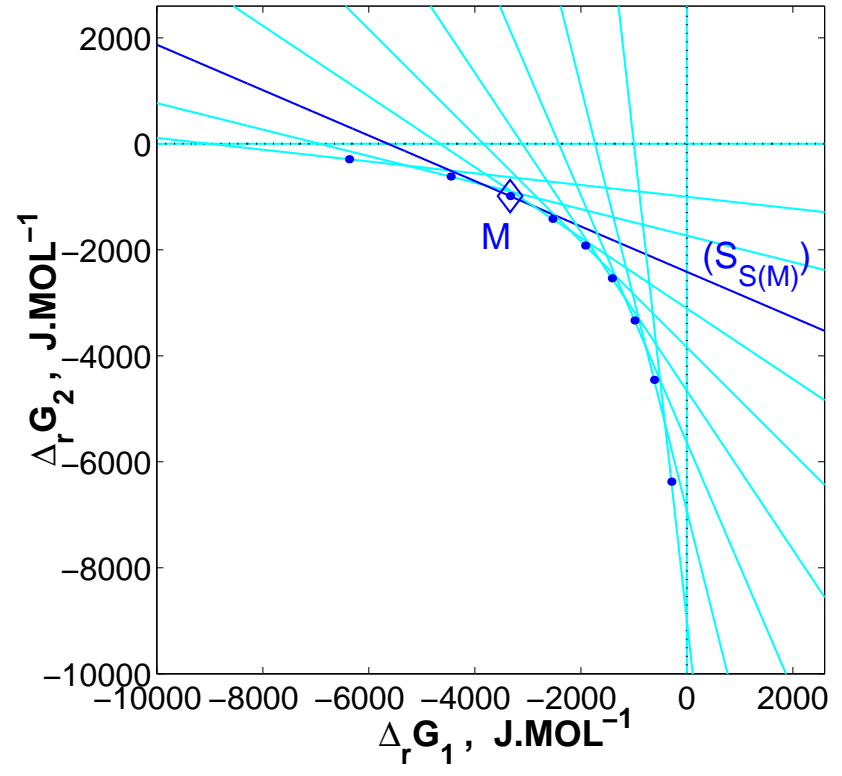

Figure 2

Stoichiometric saturations between aqueous solutions and several binary ideal solid solutions of different fixed compositions. Fluids at stoichiometric saturation with the particular ideal binary solid solution $\mathrm{M}$ follow the straight line $\left(\mathrm{S}_{\mathrm{S}(\mathrm{M})}\right)$.

solid solution of variable composition:

$$
\Omega_{\mathrm{T}_{s}}=1,
$$

where the total saturation degree of the aqueous solution with respect to an ideal solid solution is defined as ${ }^{(3)}$

$$
\Omega_{\mathrm{T}_{s}}=\sum_{\iota_{s}=1}^{\mathrm{Nem}_{\mathrm{em}}(s)} \Omega_{\iota_{s}} .
$$

Any aqueous solution which is "totally saturated" with respect to a generic solid solution is at thermodynamic equilibrium with the solid solution whose end-member mole fractions are the respective end-member saturation degrees.

Fluids at total saturation with respect to a binary ideal solid solution are represented on a curve $\left(\mathrm{S}_{\mathrm{T}}\right)$ in chemical potential diagrams (figure 3).

Since any aqueous solution which is not at total saturation with the generic solid solution is out of equilibrium, any fluid at stoichiometric saturation with a particular solid solution, and out of total saturation, presents a metastable state. Straight lines $\left(\mathrm{S}_{\mathrm{S}_{s}}\right)$ thus describe metastable states, except at the intersection with curve $\left(\mathrm{S}_{\mathrm{T}}\right)$ where true equilibrium is reached (Guy, 2003).

(3) Notice that expression (7) would be different for real solid solutions (see Michard, 1989). 


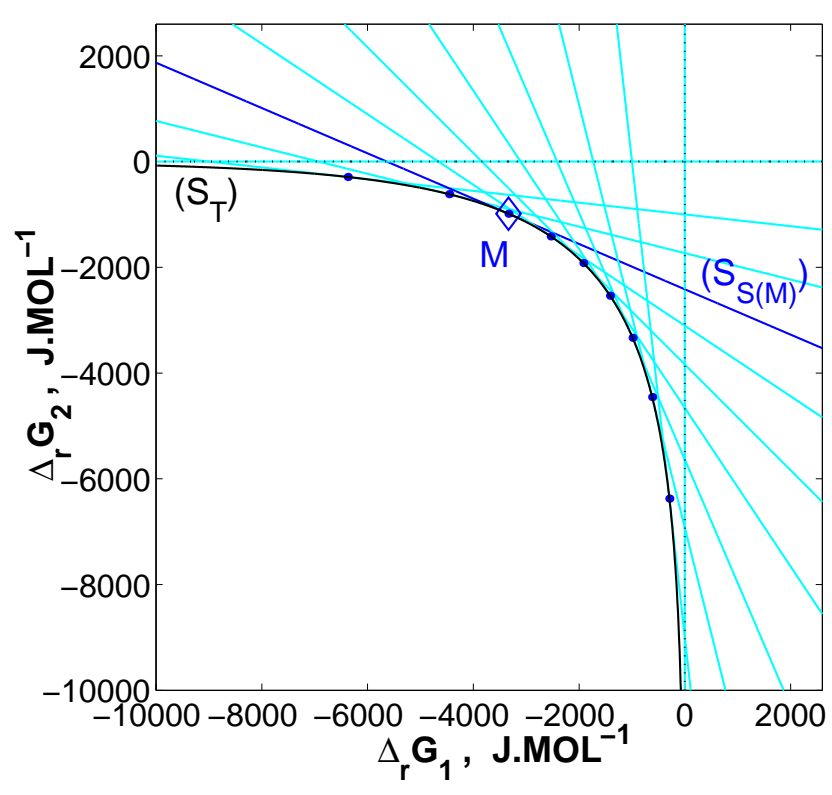

Figure 3

Total saturation and stoichiometric saturations between aqueous solutions and various binary ideal solid solutions of different fixed compositions.

Fluids at total saturation with the ideal binary solid solution $\left(\mathrm{P}_{1}, \mathrm{P}_{2}\right)$ follow curve $\left(\mathrm{S}_{\mathrm{T}}\right)$.

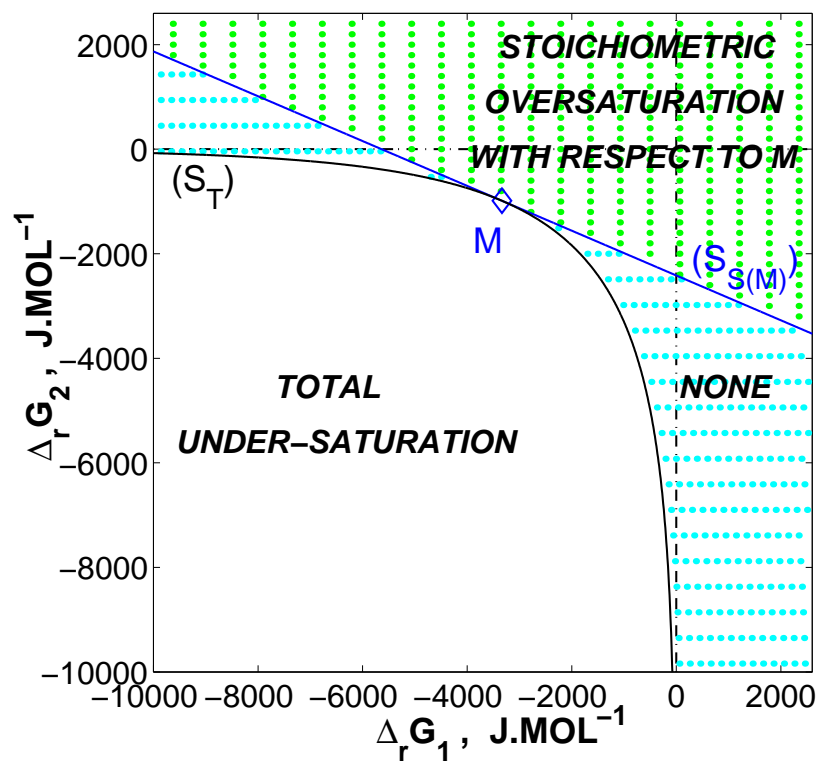

Figure 4

Departure from equilibrium (point $\mathrm{M}$ ), from total saturation (curve $\mathrm{S}_{\mathrm{T}}$ ) and from stoichiometric saturation (straight line $\mathrm{S}_{\mathrm{S}(\mathrm{M})}$ ) between aqueous solutions and a particular binary ideal solid solution of known composition $\mathrm{M}$.

"None" means that aqueous solutions are stoichiometrically undersaturated with respect to $\mathrm{M}$ and totally oversaturated with respect to the generic solid solution.

\section{SOLID SOLUTION MODELLING}

\subsection{Equilibria}

Two types of equilibrium conditions have been identified: stoichiometric saturation and total saturation. However, the corresponding states are linked: the total saturation degree of a given fluid with respect to an ideal solid solution is equal to its stoichiometric saturation degree with respect to the least soluble solid solution $^{(4)}$ (Nourtier-Mazauric, 2003), i.e.

$$
\begin{aligned}
\Omega_{\mathrm{T}_{s}} & =\max _{\left(X_{t_{s}}\right)_{t_{s}}} \Omega_{\mathrm{S}_{s\left(X_{t_{s}}\right)}}, \\
& =\Omega_{\mathrm{S}_{s\left(\widetilde{X_{s}}\right)}},
\end{aligned}
$$

where the composition $\left(\widetilde{X_{l_{s}}}\right)$ of the least soluble solid solution in the fluid is given by $(5)$

$$
\widetilde{X_{\iota_{s}}}=\frac{\Omega_{\iota_{s}}}{\Omega_{\mathrm{T}_{s}}}, \forall \iota_{s} \in\left[1, \mathrm{~N}_{\mathrm{em}}(s)\right] .
$$

(4) The least soluble solid solution in an aqueous solution is less likely to dissolve (or more likely to precipitate) than any other compound belonging to the generic solid solution. Since the saturation degree of a fluid with respect to a mineral varies inversely to the solubility of this compound in the fluid, the saturation degree of the aqueous solution with respect to the least soluble solid solution is the highest.

(5) Notice that relations (8) and (9) are valid only for ideal solid solutions.

Therefore, any aqueous solution which is at stoichiometric saturation with a particular solid solution is totally oversaturated with respect to the generic solid solution, unless the former is also at total saturation with respect to the latter, i.e. unless this solid solution is the least soluble one.

\subsection{Departure from equilibrium}

Considering equation (8), six situations relative to the saturation of the aqueous solution are to be distinguished (figure 4):

1. the aqueous solution is at equilibrium with the existing ideal solid solution $\left(\Omega_{\iota_{s}}=\overline{X_{\iota_{s}}}, \forall \iota_{s}\right)$, i.e. simultaneously at total ${ }^{(6)}$ and stoichiometric saturations $\left(\Omega_{\mathrm{T}_{s}}=1\right.$ and $\left.\Omega_{\mathrm{S}_{s\left(\overline{X_{s}}\right)}}=1\right)$; this particular solid solution is therefore the least soluble one $\left(\overline{X_{l_{s}}}=\widetilde{X_{\iota_{s}}}, \forall \iota_{s}\right)$ (point M);

2. the fluid is totally undersaturated with respect to the ideal solid solution $\left(\Omega_{\mathrm{T}_{s}}<1\right.$ and thus $\left.\Omega_{\mathrm{S}_{s\left(X_{t_{s}}\right)}}<1, \forall X_{\iota_{s}}\right)$ (void domain at the bottom on the left);

3. it is simultaneously totally saturated and stoichiometrically undersaturated with respect to the existing solid solution $\left(\Omega_{\mathrm{T}_{s}}=1\right.$ and $\left.\Omega_{\mathrm{S}_{s\left(\overline{X_{s}}\right)}}<1\right)$ (curve $\mathrm{S}_{\mathrm{T}}$ excepted point $\mathrm{M})$;

(6) i.e. at stoichiometric saturation with the least soluble solid solution 
4. it is stoichiometrically oversaturated with respect to the existing solid solution $\left(\Omega_{\mathrm{S}_{s\left(\overline{t_{s}}\right)}}>1\right.$ and thus $\left.\Omega_{\mathrm{T}_{s}}>1\right)$ (domain with vertical dotted lines, at the top on the right);

5. it is simultaneously stoichiometrically saturated with respect to the existing solid solution and totally oversaturated $^{(7)}\left(\Omega_{\mathrm{S}_{s\left(\overline{X_{s}}\right)}}=1\right.$ and $\Omega_{\mathrm{T}_{s}}>1$ ) (straight line $\mathrm{S}_{\mathrm{S}(\mathrm{M})}$ excepted point $\left.\mathrm{M}\right)$;

6. it is simultaneously stoichiometrically undersaturated with respect to the existing solid solution and totally oversaturated $\left(\Omega_{\left.\mathrm{S}_{s\left(\overline{X_{s}}\right.}\right)}<1\right.$ and $\Omega_{\mathrm{T}_{s}}>1$ ) (domains with horizontal dotted lines).

In case 1, the solid solution does neither precipitate nor dissolve, since equilibrium is reached.

In case 2, the solid solution is likely to dissolve. If a particular solid solution is already present in the geochemical system, it dissolves. As in many other works (Denis and Michard, 1983; Bourcier, 1985; Michard, 1986; Michau, 1997) this dissolution is modelled in a stoichiometric way, without variation of the solid solution composition $\left(\overline{X_{\iota_{s}}}\right)$.

In case 3 , the model implies stoichiometric dissolution of the existing solid solution, with a fixed composition $\left(\overline{X_{\iota_{s}}}\right)$.

Since the composition of a solid solution at equilibrium depends on that of the aqueous solution (see partial mass action laws (1)) and since the possible dissolution of the existing solid solution is modelled in a stoichiometric way, the solid solution can not attain thermodynamic equilibrium by precipitating with the same composition as that of the already existing phase; coprecipitation of another particular solid solution must be added to the stoichiometric dissolution of the existing solid solution to reach equilibrium.

In case 4 , the existing solid solution is likely to precipitate. The aqueous solution is then oversaturated with respect to a certain range of particular solid solutions including the existing one. For example, figure 5 shows in thick lines all particular solid solutions with respect to which a particular fluid A is stoichiometrically oversaturated ${ }^{(8)}$. However, this model chooses to precipitate only one particular solid solution, among all those which are likely to precipitate. Since the combination of stoichiometric saturation and total saturation leads to equilibrium (Nourtier-Mazauric, 2003) and since property (8) implies that total saturation is equivalent to stoichiometric saturation of the least soluble solid solution, the unique particular solid solution which precipitates according to the model is the least soluble one.

(7) consequently it is stoichiometrically oversaturated with respect to the least soluble solid solution (among others)

(8) If point $A$ was on the stoichiometric straight line $\left(\mathrm{S}_{\mathrm{S}(\mathrm{L})}\right)\left(\operatorname{resp} .\left(\mathrm{S}_{\mathrm{S}(\mathrm{N})}\right)\right)$ and in the domain where $\Delta_{r} G_{1} \geq 0$ (resp. $\Delta_{r} G_{2} \geq 0$ ), the aqueous solution represented by point $\mathrm{A}$ would be stoichiometrically oversaturated with respect to particular solid solutions whose compositions are comprised between the one of $\mathrm{L}$ and the one of pure end-member $\mathrm{P}_{1}$ (resp. between $\mathrm{N}$ and pure end-member $\mathrm{P}_{2}$ ), i.e. $X_{1}^{\mathrm{L}}<X_{1} \leq 1$, $0 \leq X_{2}<X_{2}^{\mathrm{L}}\left(\right.$ resp. $\left.0 \leq X_{1}<X_{1}^{\mathrm{N}}, X_{2}^{\mathrm{N}}<X_{2} \leq 1\right)$.

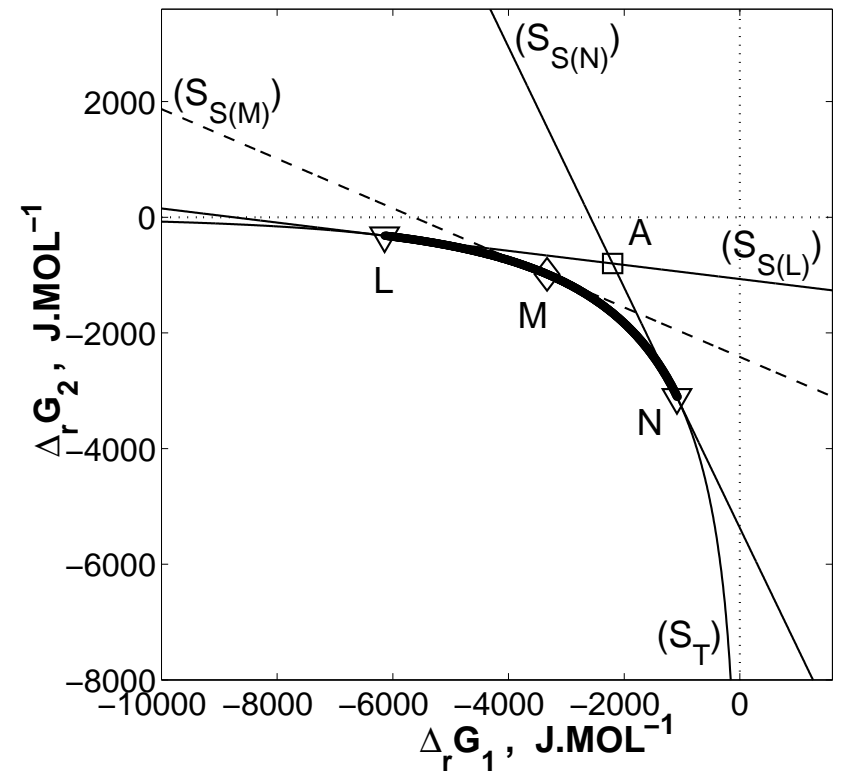

Figure 5

Stoichiometric oversaturation of an aqueous solution A with respect to the particular compound $\mathrm{M}$ belonging to the generic solid solution defined by its end-members $\left(\mathrm{P}_{1}, \mathrm{P}_{2}\right)$, stoichiometric saturation of $\mathrm{A}$ with respect to two fixed compounds, $\mathrm{L}$ and $\mathrm{N}$, belonging to the generic solid solution, and stoichiometric oversaturation of A with respect to several particular binary ideal solid solutions of fixed composition comprised between those of $\mathrm{L}$ and $\mathrm{N}$ (including $\mathrm{M}$ ).

It is important to keep in mind that all particular solid solutions with respect to which the aqueous solution is stoichiometrically oversaturated are likely to precipitate, not only the least soluble one. The choice of precipitating the least soluble solid solution (instead of all compounds with respect to which the fluid is stoichiometrically oversaturated) is sensible for ideal solid solutions because it rests on specific properties of ideal solid solutions (equations (8)-(9)) and on definition (7) of total saturation for ideal solid solutions.

In case 5 , the model implies the precipitation of the least soluble solid solution, with a known composition $\left(\widetilde{X_{\iota_{s}}}\right)$ given by equation (9).

In case 6 , the existing solid solution is likely to dissolve and a certain range of particular solid solutions (excluding the existing one) is likely to precipitate. This is illustrated on figure 6: the aqueous solution (point B) is stoichiometrically undersaturated with respect to the existing solid solution (point $\mathrm{M}$ ) and saturated with respect to two particular solid solutions (points $\mathrm{P}$ and $\mathrm{Q}$, such as $\mathrm{M}$ is outside the range $[\mathrm{P}, \mathrm{Q}])$ and is therefore oversaturated with respect to all compounds whose compositions vary between the one of $\mathrm{P}$ and the one of $\mathrm{Q}$ (thick lines). According to the previously described model, the existing solid solution dissolves stoichiometrically, with a fixed composition $\left(\overline{X_{\iota_{s}}}\right)$, and the least soluble one coprecipitates, with a known composition $\left(\widetilde{X_{l_{s}}}\right)$. 


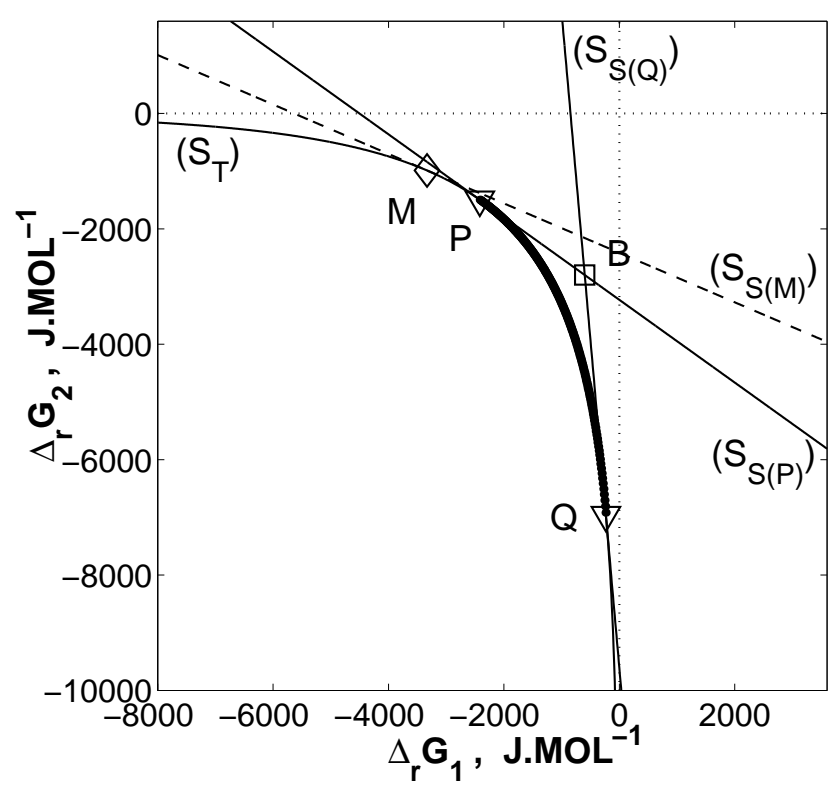

Figure 6

Total oversaturation of an aqueous solution B with respect to the generic solid solution, stoichiometric undersaturation of $B$ with respect to $M$, stoichiometric saturation of $B$ with respect to two fixed compounds, $\mathrm{P}$ and $\mathrm{Q}$, belonging to the generic solid solution, and stoichiometric oversaturation of $\mathrm{B}$ with respect to several particular binary ideal solid solutions of fixed composition comprised between those of $\mathrm{P}$ and $\mathrm{Q}$ (excluding M).

As long as a particular ideal solid solution exists in the geochemical system, whatever stoichiometric saturation state the fluid has with respect to it, and as the aqueous solution is at total oversaturation with respect to the solid solution (cases 2, 4, 5, 6), two particular solid solutions have to be taken into account at every moment: the existing one and the least soluble one.

\subsection{Kinetics}

In the case of solid solutions, dissolution and precipitation can occur simultaneously for the same phase. Both kinetic reactions are described by two reaction rates, one for the dissolution of the existing solid solution, and the other for the coprecipitation of the least soluble one. The reaction rate of the overall reaction of the solid solution is their sum (Nourtier-Mazauric, 2003).

Kinetic reaction rates depend on the departure from equilibrium, and therefore on the particular solid solution which is likely to react, i.e. on the type of reaction: stoichiometric dissolution or "total" precipitation.

If the existing ideal solid solution dissolves in a stoichiometric way, with a composition $\left(\overline{X_{\iota_{s}}}\right)$, departure from equilibrium is expressed by its stoichiometric saturation degree
$\Omega_{\mathrm{S}_{s\left(\overline{X_{t_{S}}}\right)}}$. If the least soluble ideal solid solution precipitates, with a composition $\left(\widetilde{X_{\iota_{s}}}\right)$, departure from equilibrium is expressed by its total saturation degree $\Omega_{\mathrm{T}_{s}}$.

The overall reaction of the solid solution results from the possible dissolution of the existing one and from the (co-)precipitation of the least soluble one. During a reaction step, these two particular solid solutions are considered as independent, and they react with the fluid phase at their own rates. This defines uniquely how the fluid composition changes, how much of the existing solid solution is dissolved, and how much of the least soluble one is precipitated. But the solid volume (and composition) must be updated prior to the next step in order to keep only one particular solid solution, otherwise the number of solids to be considered would increase at each time step ${ }^{(9)}$. In our model, this is realized simply by mixing together the remaining solid solution with the small amount of the least soluble one which is formed during one time step. This homogenization means that the small amount of solid which precipitates is assumed to dissolve immediately into the remaining solid, which keeps a homogeneous composition instead of becoming zoned ${ }^{(10)}$. From a physical viewpoint, this would be realistic if diffusion was rapid enough to insure a complete homogenization of zoned solids, but obviously this is an oversimplification which is justified only by calculation requirements.

The composition of the solid solution homogenized from the existing and the least soluble ones then depends on the compositions of both particular solid solutions and on both reaction rates.

\section{DIAPHORE SOLSOL}

The ideal solid solution model has been integrated into a computer code named Diaphore (Le Gallo et al. 1998; Cassou, 2000), designed to simulate the reactive transport of aqueous species in a totally water saturated medium.

The description of this code is limited here to the simplified case of an isothermal system without oxydo-reduction reactions, gases, diffusion/dispersion processes, or variation of Darcy velocity, in a one-dimension box.

The geochemical system, composed of aqueous and mineral species, is defined by a set of basis species (Westall et al., 1976; Yeh and Tripathi, 1989; Bethke, 1996).

(9) if the aqueous solution was oversaturated with respect to the least soluble solid solution during this time step

(10) Actually, if the amount of the least soluble solid solution produced during the time step is more than the one of the existing solid solution dissolved meanwhile (these amounts can be computed from the model), the overall solid grows and may get zoned. Taking into account a zonation would require that only precipitation of the least soluble solid solution occurs and that the fluid does not react with the existing solid solution. 
An initial step consists in determining the speciation of the geochemical system, according to the local equilibrium hypothesis for the aqueous solution alone.

Then the program carries out a time loop in the course of which the dynamic system is solved by the Newton-Raphson algorithm. This dynamic system, discretized in an implicit way, is strongly non-linear; it is formed by adding to solvent and electroneutrality equations several equations: the mass action laws of speciation reactions, the solute hydrodynamic transport equations and the mineral quantity variation equations linked to kinetic phenomena.

\subsection{Local equilibrium}

In a geochemical system split up into $\mathrm{N}_{\mathrm{c}}$ aqueous

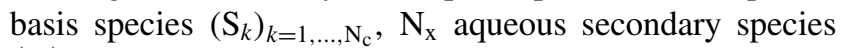
$\left(\mathrm{S}_{j}\right)_{j=\mathrm{N}_{\mathrm{c}}+1, \ldots, \mathrm{N}_{\mathrm{a}}}$ and $\mathrm{N}_{\mathrm{m}}$ mineral species $\left(\mathrm{M}_{m}\right)_{m=1, \ldots, \mathrm{N}_{\mathrm{m}}}$, speciation reactions may be written for each secondary species

$$
\mathrm{S}_{j} \rightleftharpoons \sum_{k=1}^{\mathrm{N}_{\mathrm{c}}} v_{j k} \mathrm{~S}_{k},
$$

with $v_{j k}$ the stoichiometric coefficients of basis species $S_{k}$ in the $\mathrm{S}_{j}$ dissociation reaction.

The mass action laws of speciation reactions, linearized using logarithms, link up aqueous species activities $a_{i}$ and equilibrium constants $K_{j}$ of reactions (10):

$$
\sum_{k=1}^{\mathrm{N}_{\mathrm{c}}} v_{j k} \log a_{k}-\log a_{j}=\log K_{j}, \quad \forall \mathrm{N}_{\mathrm{c}}<j \leq \mathrm{N}_{\mathrm{a}} .
$$

\section{Aqueous species activity}

Aqueous species activities $a_{i}$ depend on molalities $m_{i}$ and on activity coefficients $\gamma_{i}$ :

$$
a_{i}=\gamma_{i} m_{i} .
$$

Aqueous species activity coefficients, functions of the aqueous solution ionic strength, are determined by the extended Debye-Hückel (also called B-dot) law (Lietzke and Stoughton, 1961; Helgeson, 1969), which is applicable only for relatively dilute solutions (ionic strength less than 1) (Fritz, 1981).

\section{Water activity}

For very dilute solutions, water activity is very close to 1 . When the solution gets more concentrated, water activity lessens.

Considering that water activity in a complex solution is the same as in a $\mathrm{NaCl}$ solution of identical ionic strength, water activity of moderately concentrated aqueous solutions, whose ionic strength $I$ is less than 1 , is calculated by the following formula (Helgeson, 1969)

$$
\ln a_{\mathrm{H}_{2} \mathrm{O}}=-0.03603 I \phi,
$$

where the osmotic coefficient $\phi$ depends itself on the ionic strength and also depends on temperature (Fritz, 1975).

\subsection{Solute hydrodynamic transport}

The mass conservation equation in a simplified system, where Darcy velocity is constant and where there is neither diffusion nor dispersion processes, may be expressed for each element as

$$
\frac{\partial}{\partial t}\left(\Phi w_{\mathrm{H}_{2} \mathrm{O}} c_{l}\right)+u \cdot \nabla\left(w_{\mathrm{H}_{2} \mathrm{O}} c_{l}\right)=-\frac{\Phi}{\rho_{\mathrm{aq}}} \sum_{m=1}^{\mathrm{N}_{\mathrm{m}}} \beta_{l m} \vartheta_{m}
$$

(Lichtner, 1996), where $\Phi$ is porosity, $w_{\mathrm{H}_{2} \mathrm{O}}$ water mass fraction in the solution, $c_{l}$ element total concentration, $u$ Darcy velocity, $\rho_{\text {aq }}$ aqueous solution density and $\vartheta_{m}$ mineral kinetic reaction rates.

The total concentration of the $l$ th element in solution is a function of all aqueous species molalities:

$$
c_{l}=\sum_{i=1}^{\mathrm{N}_{\mathrm{a}}} \alpha_{l i} m_{i}
$$

\subsection{Kinetics}

\subsubsection{Mineral mass transfer equations}

Let $\mathrm{V}_{\mathrm{aq}}$ be the volume of aqueous solution, $n_{m}$ the number of moles of mineral $\mathrm{M}_{m}$ and $\vartheta_{m}$ its reaction rate related to the volume of solution:

$$
\vartheta_{m}=\frac{1}{\mathrm{~V}_{\mathrm{aq}}} \frac{\partial n_{m}}{\partial t} .
$$

The volume fraction $\phi_{m}$ of the mineral then obeys the following equation

$$
\frac{\partial \phi_{m}}{\partial t}=\Phi V_{m} \vartheta_{m},
$$

where $\Phi$ is the porosity and $V_{m}$ the molar volume of the mineral. If the latter is an ideal solid solution $\mathrm{M}_{s}$, its molar volume depends on its composition and on end-member molar volumes:

$$
V_{s}=\sum_{\iota_{s}=1}^{N_{\mathrm{em}}(s)} X_{\iota_{s}} V_{\iota_{s}}
$$

\subsubsection{Kinetic rate expressions for pure minerals}

The kinetic model integrated into Diaphore is based on the assumption that precipitation/dissolution kinetics is governed exclusively by surface reactions, i.e. molecular diffusion is not considered.

\section{Precipitation}

When the aqueous solution is oversaturated with respect to the pure mineral $\mathrm{M}_{p}$, the mineral is likely to precipitate. However, this happens only if nucleation occurs. This condition is modelled by a critical oversaturation threshold $\Gamma_{p}\left(\Gamma_{p}>1\right)$ such as the mineral, initially absent, starts precipitating as soon as $\Omega_{p}$ exceeds $\Gamma_{p}$ and continues as long as $\Omega_{p}>1$. 
The kinetic precipitation rate of the pure mineral $\mathrm{M}_{p}$ is then given by the following relation (Steefel and van Cappellen, 1990; Madé, 1994)

$$
\vartheta_{p}=k_{\mathrm{p}_{p}} s_{p}\left(\Omega_{p}^{\alpha_{p}}-1\right)^{\beta_{p}},
$$

with $k_{\mathrm{p} p}$ the kinetic precipitation constant of the $p$ th mineral, $s_{p}$ its reactive surface area ( $c f$. paragraph 3.3.4), and $\alpha_{p}$ and $\beta_{p}$ two empirical coefficients, specific to the mineral. Kinetic coefficients, which depend on temperature, are constant within the present isothermal model.

\section{Dissolution}

When the aqueous solution is undersaturated with respect to the pure mineral, i.e. when $\Omega_{p}<1$, the fixed compound dissolves with the following kinetic rate (Madé, 1994)

$$
\vartheta_{p}=-k_{\mathrm{d}_{p}} f_{p}(\mathrm{pH}) s_{p}\left(1-\Omega_{p}\right)
$$

where $f_{p}=a_{\mathrm{H}^{+}}{ }^{n_{p}^{\mathrm{H}^{+}}}$in acidic medium, 1 in neutral medium and $a_{\mathrm{OH}^{-}} n_{p}^{\mathrm{OH}^{-}}$in basic medium. $n_{p}^{\mathrm{H}^{+}}$(resp. $n_{p}^{\mathrm{OH}^{-}}$) is the stoichiometric coefficient of $\mathrm{H}^{+}$(resp. $\mathrm{OH}^{-}$) species needed to form one mole of activated complex.

\subsubsection{Kinetic rate expressions for solid solutions}

Kinetic rate laws for ideal solid solutions are based on those used for pure minerals ( $c f$. previous section).

\section{Precipitation}

When the aqueous solution is totally oversaturated with respect to the ideal solid solution $\mathrm{M}_{s}$, i.e. when $\Omega_{\mathrm{T}_{s}}>1$, the least soluble one precipitates, provided that a nucleation threshold is reached in case the solid solution still does not exist, or, alternatively, that a particular solid solution is already present in the system.

Owing to the kinetic precipitation law (19) for pure minerals and considering the remarks of paragraph 2.3 , the kinetic precipitation rate of the ideal solid solution $\mathrm{M}_{s}$ obeys the following relation

$$
\vartheta_{\mathrm{p}_{s}}=k_{\mathrm{p}_{s}} s_{s}\left(\Omega_{\mathrm{T}_{s}}{ }^{\alpha_{s}}-1\right)^{\beta_{s}} .
$$

where $k_{\mathrm{p}_{s}}$ is the kinetic precipitation coefficient of the least soluble solid solution $s$, the reactive surface area $s_{s}$ (paragraph 3.3.4) and the empirical coefficients $\alpha_{s}$ and $\beta_{s}$ are specific to the solid solution, and independent of its composition. Kinetic coefficients depend on the composition $\left(\widetilde{X_{\iota s}}\right)$ of the least soluble solid solution (Nourtier-Mazauric, 2003).

\section{Dissolution}

When the aqueous solution is stoichiometrically undersaturated with respect to the existing solid solution, i.e. when $\Omega_{\mathrm{S}_{s\left(\overline{X_{t S}}\right)}}<1$, the latter dissolves. From the kinetic dissolution law (20) for pure minerals, the following expression may be written for the kinetic dissolution rate of the existing ideal solid solution:

$$
\vartheta_{\mathrm{d}_{s}}=-k_{\mathrm{d}_{s}} f_{s}(\mathrm{pH}) s_{s}\left(1-\Omega_{\mathrm{S}_{s\left(\overline{t_{s}}\right)}}\right),
$$

where the function $f_{s}$ depends on $\mathrm{pH}$ as $f_{p}$ in section 3.3.2. The kinetic dissolution constant $k_{\mathrm{d}_{s}}$ is independent of the composition of the existing solid solution; it is specific to the type of solid solution (e.g. carbonate).

\section{Overall reaction}

Since dissolution and coprecipitation are likely to occur simultaneously, the overall reaction rate of the solid solution is given by

$$
\vartheta_{s}=\vartheta_{\mathrm{p}_{s}}+\vartheta_{\mathrm{d}_{s}} .
$$

\subsubsection{Petrophysical model}

It is assumed, in a very simplified manner, that rocks can be represented as a packing of ideal, disjoined spherical grains. The mineral growth is thus modelled by increasing either (1) the number or (2) the radius of spheres and fixing the other parameter.

Usually, the first option is chosen for clays, made of small particles, while the latter is preferred for primary skeleton minerals, like quartz and $\mathrm{K}$-feldspar.

Let $r_{m}$ the grain radius and $d_{m}$ the number of grains by solution volume unit. Geometric surface area by solution volume unit $S_{m}$ can be deduced from geometrical relations for spheres:

$$
\left\{\begin{array}{l}
S_{m}=\frac{3}{r_{m}} \frac{\phi_{m}}{\Phi} \\
d_{m}=\frac{3}{4 \pi r_{m}^{3}} \frac{\phi_{m}}{\Phi}
\end{array}\right.
$$

if the sphere radius is constant,

$$
\left\{\begin{array}{l}
S_{m}=4 \pi d_{m}\left(\frac{3}{4 \pi d_{m}} \frac{\phi_{m}}{\Phi}\right)^{2 / 3} \\
r_{m}=\left(\frac{3}{4 \pi d_{m}} \frac{\phi_{m}}{\Phi}\right)^{1 / 3}
\end{array}\right.
$$

if the number of spheres is constant.

The reactive surface area $s_{m}$, i.e. the surface which is actually involved in reactions, is approximated by multiplying the geometric surface area by a reactive coefficient $c_{m}$, that depends on both the mineral and the particular rock fabric (Brosse et al., this issue):

$$
s_{m}=c_{m} S_{m} .
$$


TABLE 1

Initial mineral system.

\begin{tabular}{|c|c|c|c|c|c|c|c|c|c|c|c|c|}
\hline mineral & chemical formula & $\begin{array}{l}\phi_{m} \\
(\%)\end{array}$ & $\begin{array}{c}s_{m} \\
\left(\mathrm{~m}^{2} / \mathrm{l}\right)\end{array}$ & $c_{m}$ & $\begin{array}{c}k_{\mathrm{d}_{m}} \\
\left(\mathrm{~mol} / \mathrm{m}^{2} / \text { year }\right)\end{array}$ & $\begin{array}{c}k_{\mathrm{p}_{m}} \\
\left(\mathrm{~mol} / \mathrm{m}^{2} / \text { year }\right)\end{array}$ & $\alpha_{m}$ & $\beta_{m}$ & $\Gamma_{m}$ & $\begin{array}{l}\text { texture } \\
\text { model }\end{array}$ & $\begin{array}{c}V_{m} \\
\left(\mathrm{~cm}^{3} / \mathrm{mol}\right)\end{array}$ & $\log K_{m}{ }^{\text {(a) }}$ \\
\hline \multicolumn{13}{|c|}{ fixed compounds } \\
\hline Quartz & $\mathrm{SiO}_{2}$ & 69 & 45 & 1. & $1.6 \mathrm{E}-5$ & $1.6 \mathrm{E}-5$ & 1. & 1. & 1. & $\operatorname{cst} d_{s}$ & 22.688 & -3.503 \\
\hline Kaolinite & $\mathrm{Si}_{2} \mathrm{Al}_{2} \mathrm{O}_{5}(\mathrm{OH})_{4}$ & 1 & 80 & 1. & $4.5 \mathrm{E}-5$ & $4.5 \mathrm{E}-5$ & 1. & 1. & 1. & $\operatorname{cst} r_{s}$ & 99.52 & 4.550 \\
\hline K-Feldspar & $\mathrm{KAlSi}_{3} \mathrm{O}_{8}$ & 3 & 3.5 & 1. & $5.5 \mathrm{E}-4$ & $5.5 \mathrm{E}-4$ & 1. & 1. & 1. & $\operatorname{cst} d_{s}$ & 108.87 & -0.514 \\
\hline Albite & $\mathrm{NaAlSi}_{3} \mathrm{O}_{8}$ & 1 & 1.5 & 1. & $5.5 \mathrm{E}-4$ & $5.5 \mathrm{E}-4$ & 1. & 1. & 1. & $\operatorname{cst} r_{s}$ & 100.07 & 1.990 \\
\hline Calcite & $\mathrm{CaCO}_{3}$ & 4 & 5.5 & 1. & $2.9 \mathrm{E}-1$ & $2.9 \mathrm{E}-1$ & 1. & 1. & 1. & $\operatorname{cst} d_{s}$ & 36.934 & 3.210 \\
\hline Biotite & $\mathrm{Si}_{2.8} \mathrm{Al}_{1.4} \mathrm{Mg}_{0.8} \mathrm{Fe}_{2} \mathrm{O}_{10}(\mathrm{OH})_{2} \mathrm{~K}$ & 2.2 & 15.3 & 1. & $4.7 \mathrm{E}-6$ & $4.7 \mathrm{E}-6$ & 1. & 1. & 1. & $\operatorname{cst} r_{s}$ & 154.1 & 14.69 \\
\hline \multicolumn{13}{|c|}{ (initial) solid solutions } \\
\hline $\mathrm{Mg}$-Fe-chlorite & $\mathrm{Si}_{3} \mathrm{Al}_{2}\left(\mathrm{Fe}_{2.5} \mathrm{Mg}_{2.5}\right) \mathrm{O}_{10}(\mathrm{OH})_{8}$ & 0.08 & 0.0587 & 1. & $4.7 \mathrm{E}-6$ & $\sim 4.7 \mathrm{E}-6^{(\mathrm{b})}$ & 1. & 1. & 1. & cst $r_{s}$ & $211.1^{(\mathrm{c})}$ & $14.99^{\text {(c) }}$ \\
\hline Mg-ankerite & $\mathrm{Ca}\left(\mathrm{Fe}_{0.95} \mathrm{Mg}_{0.05}\right)\left(\mathrm{CO}_{3}\right)_{2}$ & 0.88 & 0.587 & 1. & $1.1 \mathrm{E}-1$ & $\sim 1.1 \mathrm{E}-1^{(\mathrm{b})}$ & 1. & 1. & 1. & $\operatorname{cst} d_{s}$ & $69.366^{(\mathrm{c})}$ & $1.544^{(\mathrm{c})}$ \\
\hline
\end{tabular}

(a) Classical equilibrium constant for pure minerals, apparent overall solubility product of the existing solid solution (Tardy and Fritz, 1981) for initial solid solutions.

(b) Parameter which depends on the composition of the least soluble solid solution (here at initial time).

(c) Parameter which depends on the composition of the existing solid solution (here at initial time).

The reactive coefficient, generally less than 1 , may take into account contacts between contiguous grains, which decrease the overall surface area, or mineral surface partial occultation due to precipitation of minerals over preexisting grains.

\section{APPLICATION}

In the context of $\mathrm{CO}_{2}$ sequestration into saline aquifers of the subsurface, the computer code has been used to study the evolution of a glauconitic sandstone aquifer ${ }^{(11)}$ (table 1), in which a sea water enriched in carbonates (table 2) is injected ${ }^{(12)}$ continuously, at $60^{\circ} \mathrm{C}$ and 100 bar.

In this system, exchanges between iron and magnesium are studied in a peculiar way by considering two minerals as ideal solid solutions: (1) a magnesian ankerite, whose endmembers are pure ankerite $\mathrm{CaFe}\left(\mathrm{CO}_{3}\right)_{2}$ and pure dolomite $\mathrm{CaMg}\left(\mathrm{CO}_{3}\right)_{2}$, and (2) a ferro-magnesian chlorite, whose end-members are $\mathrm{Si}_{3} \mathrm{Al}_{2} \mathrm{Fe}_{5} \mathrm{O}_{10}(\mathrm{OH})_{8}$, referred to as "Fechlorite", and $\mathrm{Si}_{3} \mathrm{Al}_{2} \mathrm{Mg}_{5} \mathrm{O}_{10}(\mathrm{OH})_{8}$, referred to as "Mgchlorite" ${ }^{(13)}$.

Thermodynamic and kinetic data originate from $\mathrm{Xu}$ et al. (2004), except equilibrium constants for biotite, chlorite (Tardy and Garrels, 1974) and ankerite (Woods and Garrels, 1992).

The renewal of acidic fluid raises the dissolution of carbonates in 130 years (figure 7). First, calcite is partially

(11) based on a specific aquifer of Alberta (Canada)

(12) at a Darcy velocity equal to $1 \mathrm{~m} / \mathrm{year}$, in a one-dimension-box of $1 \mathrm{~m}$-length

(13) Nota: Although only binary solid solutions are taken into account in this example, Diaphore SolSol is able to simulate the evolution of solid solutions whose number of end-members is more than 2 .
TABLE 2

Initial aqueous system: $\mathrm{pH}$ and concentrations of elements $\left(\mathrm{mol} / \mathrm{kg}\left(\mathrm{H}_{2} \mathrm{O}\right)\right)$ in the injected aqueous solution.

\begin{tabular}{|c|c|c|c|c|}
\hline $\mathrm{pH}$ & $\mathrm{C}$ & $\mathrm{Na}$ & $\mathrm{Cl}$ & $\mathrm{Ca}$ \\
\hline 3.64 & 1.10799 & 0.554755 & 0.70697 & $0.12175 \mathrm{E}-1$ \\
\hline \hline $\mathrm{K}$ & $\mathrm{Mg}$ & $\mathrm{Fe}$ & $\mathrm{Si}$ & $\mathrm{Al}$ \\
\hline $0.12196 \mathrm{E}-1$ & $0.620390 \mathrm{E}-1$ & $0.954 \mathrm{E}-5$ & $0.119 \mathrm{E}-3$ & $0.25050 \mathrm{E}-4$ \\
\hline
\end{tabular}

replaced by the mixed carbonate $\mathrm{Mg}$-ankerite. The latter gets richer in magnesium brought by sea water (figure 8). These reactions result in an overall dissolution of carbonates, which drives the aqueous solution richer in carbon and calcium (compare table 2 and figure 9) right from the start of the simulation ${ }^{(14)}$

When calcite has disappeared ${ }^{(15)}$, low $\mathrm{pH}$ attacks $\mathrm{Mg}$ ankerite, which dissolves getting richer in iron and releasing magnesium. Simultaneously, chlorite precipitates getting richer in iron. As the amount of carbonates is much less important from 20 years, the dissolution of carbonates lessens, resulting in a lower concentration of the aqueous solution in carbon and calcium ions.

After 150 years, the geochemical system does not evolve much any longer, and the composition of the current aqueous solution gets very close to that of the injected sea water (compare figure 9 and table 2).

(14) These results must be qualified since the B-dot activity model used in Diaphore SolSol (see section 3.1) is not as relevant for sea water as Pitzer model (Kervévan et al., this issue).

(15) after 27 years 


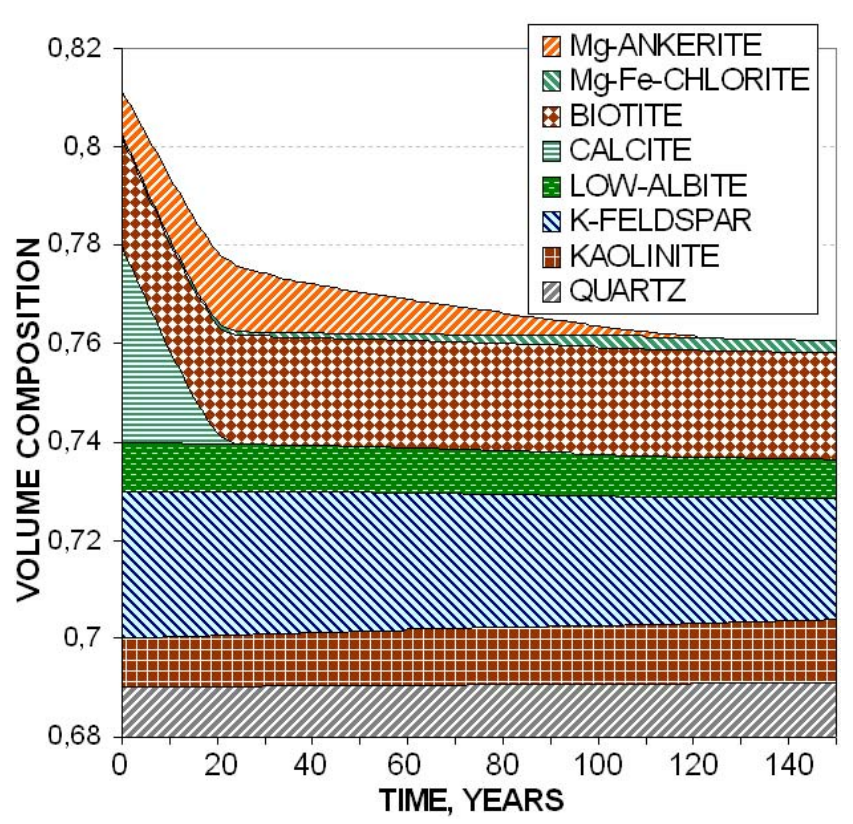

Figure 7

Mineral composition of the system (sum of volume fractions of minerals) until 150 years.

The void domain above the Mg-ankerite profile corresponds to porosity.

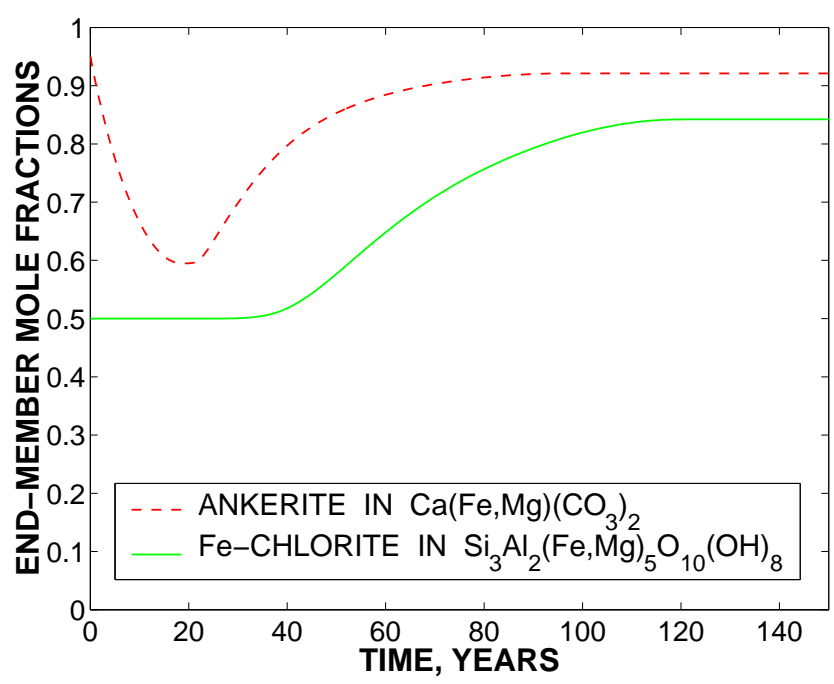

Figure 8

Composition of both solid solutions (mole fraction of each ferrous end-member) until 150 years.

The evolution of aqueous solution and solid solutions is illustrated on chemical potential diagrams (figures 11 to 14).

Fluids are represented by points of coordinates $\left(\Delta_{r} G_{1}\right.$, $\left.\Delta_{r} G_{2}\right)$, defined by equations (2) ${ }^{(16)}$, while current solid

(16) Each saturation degree $\Omega_{\iota_{s}}$ of the solid solution end-member is computed by Diaphore SolSol from its ionic activity product (reckoned

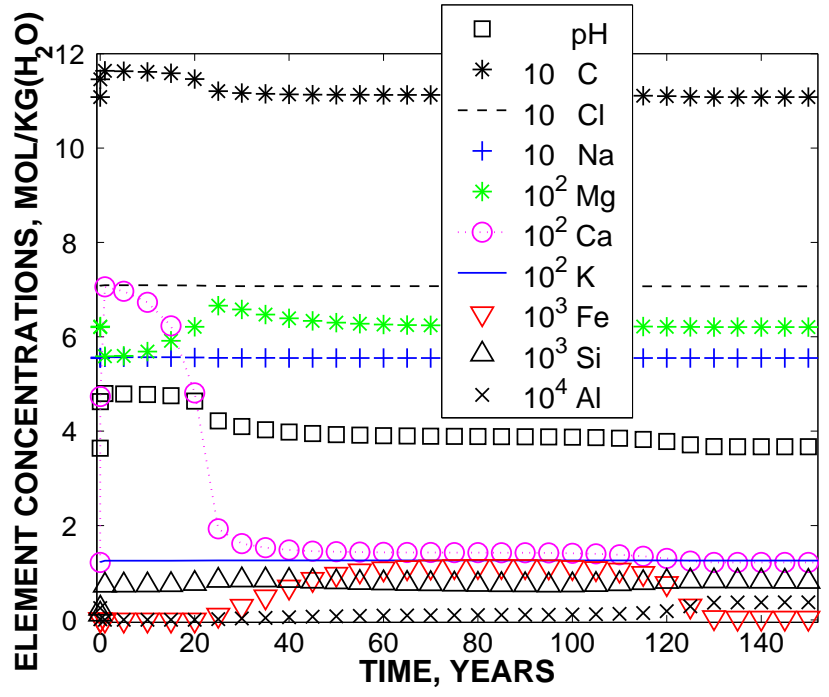

Figure 9

Composition of the aqueous solution until 150 years.

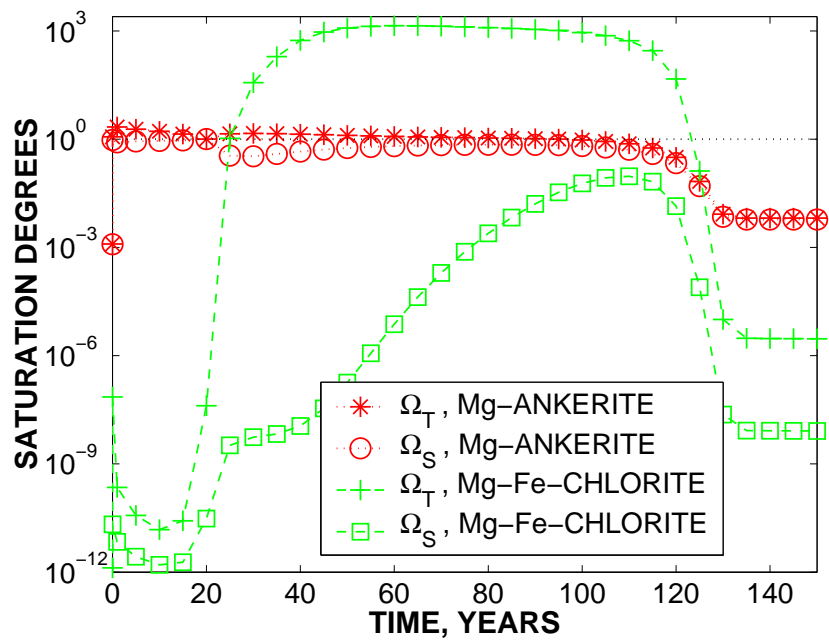

Figure 10

Stoichiometric and total saturation degrees $\left(\Omega_{\mathrm{S}_{s}}\right.$ and $\Omega_{\mathrm{T}_{s}}$ resp.) of the aqueous solution with respect to both solid solutions, until 150 years.

solutions are displayed on the total saturation curve $\left(\mathrm{S}_{\mathrm{T}}\right)$, as if they were at thermodynamic equilibrium with the aqueous solution ( $c f$. relations (3)).

Examine the case of magnesian ankerite for instance. After 4 months, the representative point of the aqueous solution $\left(\mathrm{A}_{4 \mathrm{~m}}\right)$ is over the total saturation curve of Mg-ankerite $\left(\mathrm{S}_{\mathrm{T}_{\mathrm{M}}}\right)$ in figure 12 , because the fluid is totally oversaturated with respect to this solid solution $\left(\Omega_{\mathrm{T}_{\mathrm{Mg} \text {-ankerite }}}>1\right.$ in figure 10). At the same time, $\mathrm{A}_{4 \mathrm{~m}}$ is under the stoichiometric

notably from solute concentrations) and the equilibrium constant of the dissociation reaction of the end-member in the aqueous solution. 


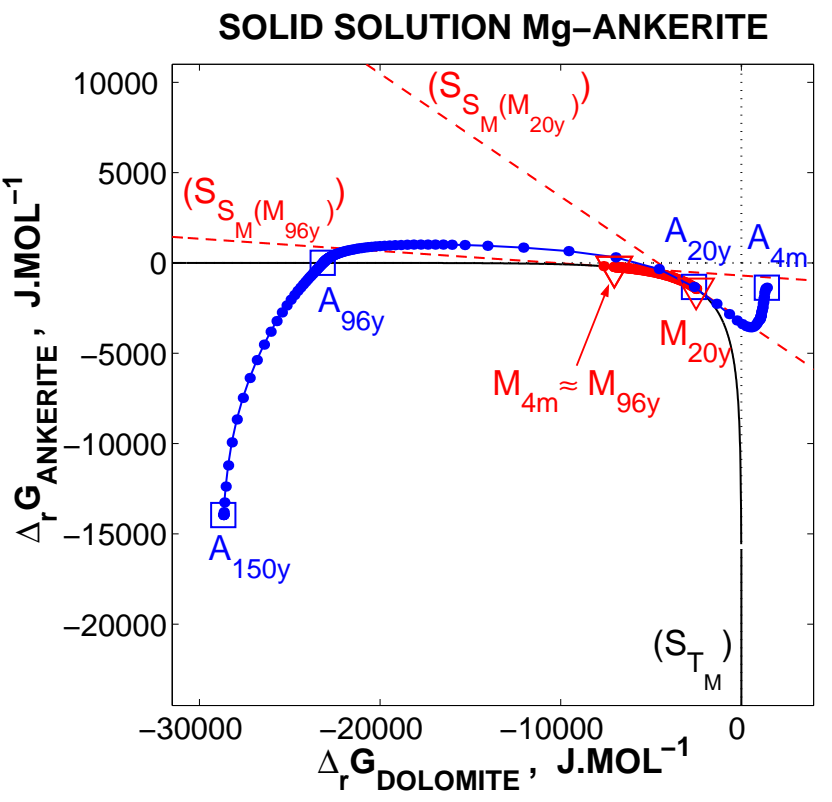

Figure 11

Evolution of the aqueous solution (A) and the existing solid solution of $\mathrm{Mg}$-ankerite $(\mathrm{M})$ between 4 months $(4 \mathrm{~m})$ and 150 years (150y). Marks 20y and 96y mean 20 and 96 years resp. Nota: $\mathrm{M}_{150 \mathrm{y}} \approx \mathrm{M}_{96 \mathrm{y}} \approx \mathrm{M}_{4 \mathrm{~m}}$, i.e. the existing solid solution has approximately the same composition at the beginning and at the end of the simulation.

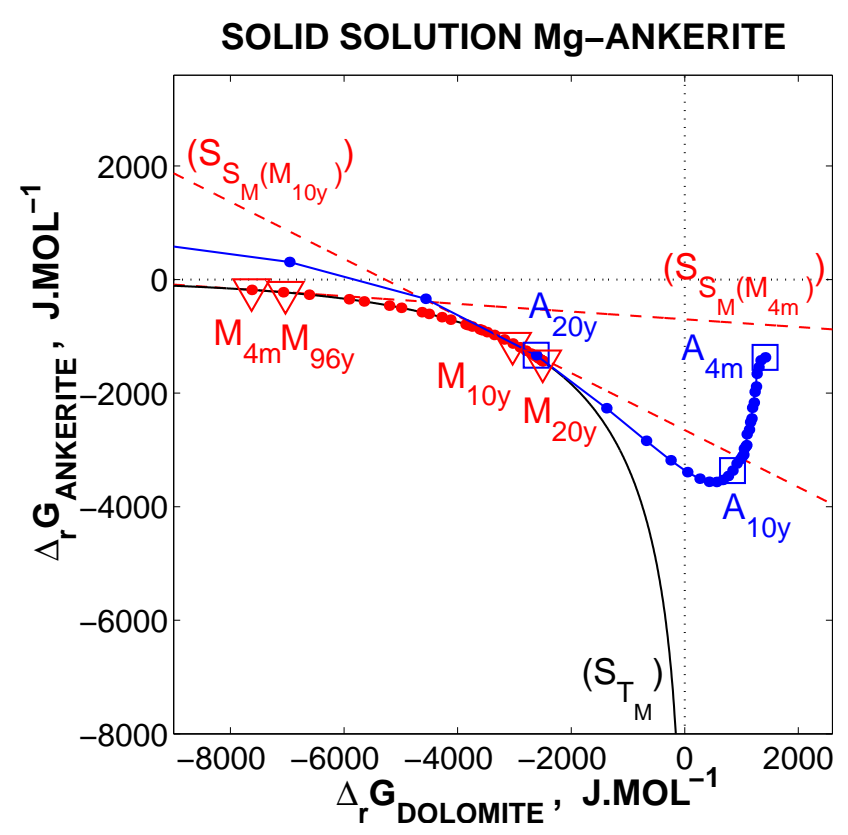

Figure 12

Zoom: Evolution of the aqueous solution (A) and the existing solid solution of $\mathrm{Mg}$-ankerite $(\mathrm{M})$ between 4 months $(4 \mathrm{~m})$ and 96 years $(96 y)$.
SOLID SOLUTION Mg-Fe-CHLORITE

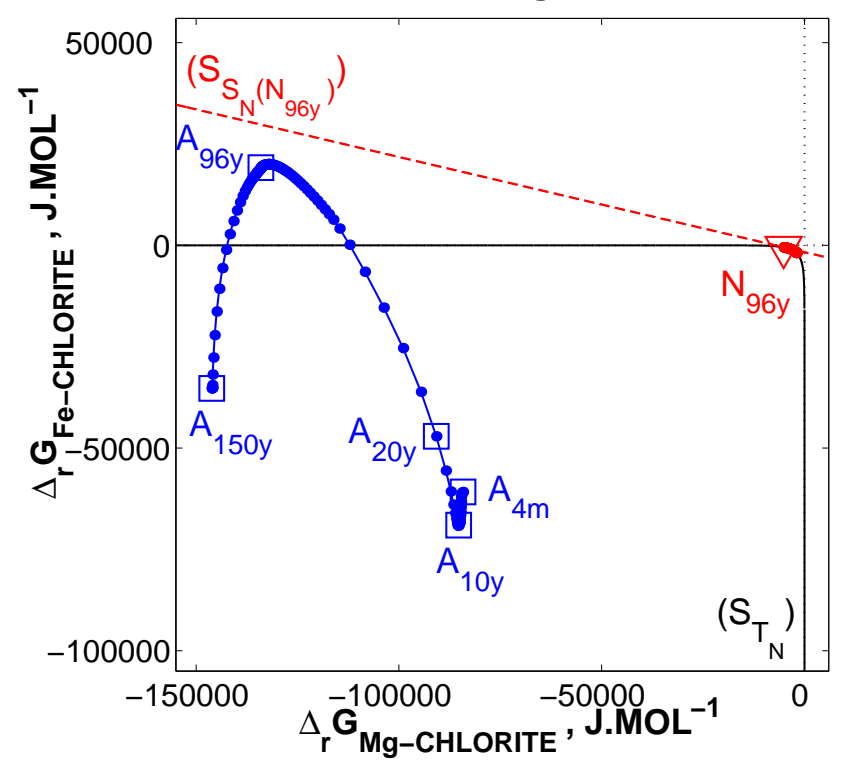

Figure 13

Evolution of the aqueous solution (A) and the existing solid solution of $\mathrm{Mg}-\mathrm{Fe}$-chlorite $(\mathrm{N})$ between 4 months and 150 years. See figure 14 to visualize solid solution compositions.

\section{SOLID SOLUTION Mg-Fe-CHLORITE}

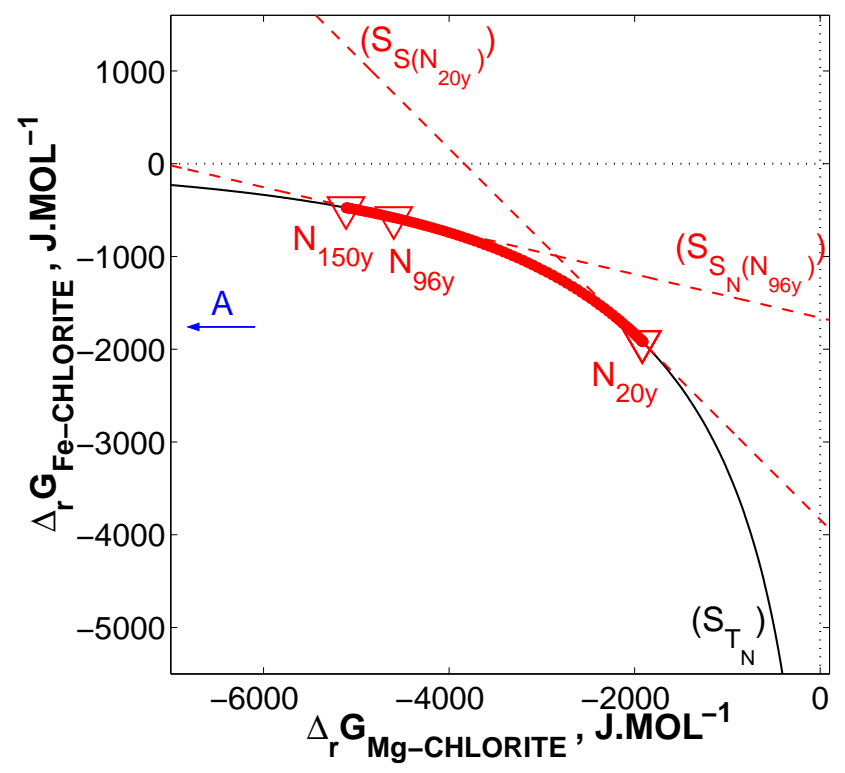

Figure 14

Zoom: Evolution of the existing solid solution of Mg-Fechlorite $(\mathrm{N})$ between 4 months and 150 years. The aqueous solution (A) is situated far on the left, under the stoichiometric saturation straight lines (see figure 13).

Nota: The composition of the existing solid solution $(\mathrm{N})$ is invariant until around 30 years, so $\mathrm{N}_{20 \mathrm{y}} \approx \mathrm{N}_{4 \mathrm{~m}}$. 
saturation straight line $\left(\mathrm{S}_{\mathrm{S}_{\mathrm{M}}\left(\mathrm{M}_{4 \mathrm{~m}}\right)}\right)$ of the aqueous solution with respect to the existing solid solution (figure 12), because the fluid is stoichiometrically undersaturated with respect to the latter $\left(\Omega_{\mathrm{S}_{\mathrm{Mg} \text {-ankerite }}}<1\right.$ in figure 10$)$. Owing to the total oversaturation of the aqueous solution with respect to $\mathrm{Mg}$ ankerite, after 4 months the least soluble carbonate solid solution precipitates, with a composition $\left(\widetilde{X}_{\text {ankerite }}, \widetilde{X}_{\text {dolomite }}\right)$ given by equation (9)

$$
\left\{\begin{array}{l}
\widetilde{X}_{\text {ankerite }}=\frac{\Omega_{\text {ankerite }}}{\Omega_{\mathrm{T}_{\text {Mg-ankerite }}}}=\frac{\Omega_{\text {ankerite }}}{\Omega_{\text {ankerite }}+\Omega_{\text {dolomite }}}, \\
\widetilde{X}_{\text {dolomite }}=1-\widetilde{X}_{\text {ankerite }},
\end{array}\right.
$$

i.e. $\left(\widetilde{X}_{\text {ankerite }}, \widetilde{X}_{\text {dolomite }}\right) \approx(0.73,0.27)$, while the existing solid solution dissolves with a fixed composition $\left(\bar{X}_{\text {ankerite }}, \bar{X}_{\text {dolomite }}\right) \approx(0.92,0.08)$, richer in pure ankerite than the least soluble one. The homogenization of the two particular solid solutions enriches the preexisting solid solution in magnesium. Representative points of the current $\mathrm{Mg}$-ankerite thus move towards the right of the chemical potential diagram (see relative positions of points $\mathrm{M}_{4 \mathrm{~m}}$ and $\mathrm{M}_{10 \mathrm{y}}$ in figure 12). Since the kinetic constants $k_{\mathrm{p}_{m}}$ and $k_{\mathrm{d}_{m}}$ of Mg-ankerite are very high (as those of carbonates, $c f$. table 1), precipitation and dissolution are fast despite the weak departure from total saturation and stoichiometric saturation respectively. Therefore, the composition of the carbonate solid solution changes rapidly (see figure 8).

Simultaneously, the aqueous solution is very strongly undersaturated with respect to the solid solution of $\mathrm{Mg}-\mathrm{Fe}$ chlorite (figures 13 and 10). The initial existing chlorite thus dissolves stoichiometrically, without changing its initial composition $\left(\bar{X}_{\mathrm{Fe}-\text { chlorite }}, \bar{X}_{\mathrm{Mg} \text {-chlorite }}\right)=(0.5,0.5)$.

Since the kinetic constant of Mg-Fe-chlorite is very low relatively to that of magnesian ankerite (table 1), the enrichment in magnesium of the overall solid solution of $\mathrm{Mg}$ ankerite leads to a decrease of magnesium in the aqueous solution (figure 9), although the dissolution of the solid solution of chlorite releases magnesium in the fluid.

For 20 years, the fluid keeps simultaneously oversaturated with respect to the least soluble magnesian ankerite and undersaturated with respect to the existing one. The homogenization of the precipitating and dissolving particular solid solutions still implies an enrichment of $\mathrm{Mg}$-ankerite in magnesium, since the current one is very Fe-rich and the least soluble one is richer in magnesium. As the aqueous solution gets closer to total saturation with respect to the carbonate solid solution, the precipitation of the latter lessens and consumes less magnesium. The $\mathrm{Mg}$ concentration thus increases in the aqueous solution, since the injected sea water is richer in magnesium than the water in place and since the stoichiometric dissolution of $\mathrm{Mg}$-Fe-chlorite still releases magnesium.

Around 20 years, the representative points of the fluid and of the existing Mg-ankerite are almost identical
$\left(\mathrm{A}_{20 \mathrm{y}} \approx \mathrm{M}_{20 \mathrm{y}}\right.$ in figures 11 and 12). They thus belong simultaneously to the total saturation curve $\left(\mathrm{S}_{\mathrm{T}_{\mathrm{M}}}\right)$ and to the stoichiometric saturation straight line $\left(\mathrm{S}_{\mathrm{S}_{\mathrm{M}}\left(\mathrm{M}_{20 \mathrm{y}}\right)}\right)$ : $\Omega_{\mathrm{T}_{\mathrm{Mg} \text {-ankerite }}} \approx 1$ and $\Omega_{\mathrm{S}_{\mathrm{Mg} \text {-ankerite }}} \approx 1$ in figure 10. Therefore, equilibrium between the magnesian ankerite and the aqueous solution is approximately reached. The current carbonate solid solution is thus the least soluble one in this fluid.

This equilibrium state between fluid and $\mathrm{Mg}$-ankerite is temporary. As calcite disappears, transfers of carbonates and calcium ions from the solid to the aqueous solution are not sufficient any more for their aqueous concentrations to stay at the high values they reached at the very beginning of the reaction (figure 9), since calcite is not completely replaced by $\mathrm{Mg}$-ankerite and since $\mathrm{C}$ and $\mathrm{Ca}$ concentrations are much lower in the injected sea water than in the preexisting fluid. The decrease of carbon and calcium in the aqueous solution leads to a decrease of $\mathrm{pH}$. As the fluid changes, the representative points of the aqueous solution (A) and of the current carbonate solid solution (M) move away from each other (figure 11). Since points A move slightly to the top and strongly to the left after 20 years, the saturation degree of the fluid with respect to the pure ankerite end-member increases slightly and that with respect to the pure dolomite one decreases strongly ${ }^{(17)}$. Therefore, according to formula (27), the least soluble solid solution gets poorer in magnesium. Since the aqueous solution is again totally oversaturated and stoichiometrically undersaturated with respect to the carbonate solid solution (figure 10), the least soluble one precipitates and the existing one dissolves stoichiometrically. The homogenization of the two particular solid solutions thus drives $\mathrm{Mg}$-ankerite richer in iron (corroborated by figure 8 ). Since the existing carbonate solid solution was enriched in magnesium during 20 years and depleted in magnesium after 20 years, the point $\left(\mathrm{M}_{20 \mathrm{y}}\right)$ constitutes a cusp of the trajectory followed by the the solid solution on the total saturation curve $\left(\mathrm{S}_{\mathrm{T}_{\mathrm{M}}}\right)$ (figure 11).

Between 25 and 123 years, the fluid is totally oversaturated with respect to the solid solution of $\mathrm{Mg}$-Fe-chlorite (figure 10). This is illustrated in figure 13 by the positions of the representative points of the aqueous solution (A), over the saturation curve ${ }^{(18)}\left(\mathrm{S}_{\mathrm{T}_{\mathrm{N}}}\right)$. Therefore the least soluble chlorite solid solution precipitates, with the composition

$$
\left\{\begin{array}{l}
\widetilde{X}_{\text {Fe-chlorite }}=\frac{\Omega_{\text {Fe-chlorite }}}{\Omega_{\text {Fe-chlorite }}+\Omega_{\text {Mg-chlorite }}}, \\
\widetilde{X}_{\text {Mg-chlorite }}=1-\widetilde{X}_{\text {Fe-chlorite }} .
\end{array}\right.
$$

Since the overall Gibbs free energy of dissociation of the $\mathrm{Mg}$-chlorite end-member is extremely low comparatively to that of the Fe-chlorite end-member, the saturation degree

(17) because the overall Gibbs free energy of dissociation of each endmember in the aqueous solution is linked to its saturation degree

(18) Far from origin, the saturation curve $\left(\mathrm{S}_{\mathrm{T}}\right)$ is very close to both axes of the chemical potential diagram, since its asymptotes are these axes. 
of Fe-chlorite is much higher than that of Mg-chlorite, and the least soluble $\mathrm{Mg}$-Fe-chlorite is almost identical to $\mathrm{Fe}$ chlorite. Simultaneously, the fluid is still stoichiometrically undersaturated with respect to the current solid solution (figures $13^{(19)}$ and 10), whose composition is still half Fechlorite half Mg-chlorite until 25 years. The homogenization of the two particular solid solutions thus enriches the chlorite solid solution in iron (figure 8). This is illustrated in figure 13 by the shift of points $(\mathrm{N})$ representative of the current chlorite solid solution to the left. Since Mg-ankerite releases less magnesium in the fluid as its mole fraction in iron increases, and since the chlorite kinetics is slow, the concentration of magnesium in the aqueous solution gets closer to that of the injected sea water (figure 9), whose concentration is lower, despite the release of magnesium by the dissolving existing chlorite.

From 96 years forward, the fluid is totally undersaturated with respect to $\mathrm{Mg}$-ankerite (figure 10): in figure 11, representative points of the aqueous solution (A) are below the total saturation curve $\left(\mathrm{S}_{\mathrm{T}_{\mathrm{M}}}\right)$. The composition of the carbonate solid solution therefore stays invariant as it dissolves stoichiometrically (without simultaneous coprecipitation). In the same way, the chlorite solid solution dissolves (without coprecipitating) with a fixed composition from 124 years forward, as its total saturation degree passes below 1 .

From 131 years forward, carbonates are completely dissolved. Thus the concentrations of respectively carbonates and calcium in the aqueous solution, which have reached those in the injected sea water, do not vary any longer. The release of magnesium and iron by the dissolution of biotite and $\mathrm{Mg}$-Fe-chlorite is very low because of their low kinetic constants. Since the current aqueous solution and the injected sea water have very close compositions, aqueous concentrations do not any longer evolve significantly.

\section{CONCLUSION}

This application illustrated the ideal solid solution model proposed in this paper, as the overall behaviour of two solid solutions, a carbonate and a chlorite one, was explained.

Moreover, chemical potential diagrams proved to be very useful tools to illustrate the evolution of the system in the case of binary solid solutions.

Since minerals of fixed composition do not cover the overall field of variation of natural solid compositions, the integration of solid solutions - besides fixed compounds into geochemical modelling allows to discuss more precisely the evolution of natural systems. The Diaphore SolSol computer code is designed to study theoretic behaviour of ideal solid solutions and to model complex systems which are known to contain mineral phases which may have important

(19) see for instance the position of point $\mathrm{A}_{96 \mathrm{y}}$, under the stoichiometric saturation straight line $\left(\mathrm{S}_{\mathrm{S}_{\mathrm{N}}\left(\mathrm{N}_{96 \mathrm{y}}\right)}\right)$ of the existing solid solution variations of compositions when reacting with circulating fluids or diffusing elements.

In the future, the computer code may allow to evaluate different precipitation kinetic rate laws, especially with regard to the choice of the precipitating particular solid solution. Actually, other rules than that of precipitating the least soluble solid solution may be valid (see Guy, 2003). In other respects, nucleation may constrain the composition of the precipitating solid solution so that this mineral is the one which nucleates the best.

\section{ACKNOWLEDGEMENTS}

This work has been supported by the École nationale supérieure des mines (School of mines) of Saint-Etienne and the Institut Français du Pétrole (French Petroleum Institute).

\section{REFERENCES}

Bethke, C.M. (1996) Geochemical reaction modeling. Oxford University Press, New York, 397 p.

Blanc, Ph. (1996) Organisation de l'empilement des minéraux interstratifiés illite/smectite : modélisation thermodynamique et application au domaine expérimental. PhD Thesis, Université Louis Pasteur de Strasbourg, 205 p.

Blanc, Ph., Bieber, A., Fritz, B. and Duplay, J. (1997) A short range interaction model applied to illite/smectite mixed-layer minerals. Phys. Chem. Minerals, 24, 574-581.

Bourcier, W.L. (1985) Improvements in the solid solution modeling capabilities of the EQ3/6 geochemical code. Lawrence Livermore National Laboratory, UCID-20587, DE86 004494.

Brosse, E., Magnier, C. and Vincent, B. (2005) Modelling fluid-rock interaction induced by the percolation of $\mathrm{CO}_{2}$-enriched solutions in core samples: 1 . The role of reactive surface area. Oil \& Gas Science and Technology - Rev. IFP, this issue.

Cassou, C. (2000) Modélisation numérique des interactions eauroche : optimisation du code de calcul DIAPHORE et application à la diagenèse minérale des réservoirs. PhD Thesis, Ecole Nationale Supérieure d'Arts et Métiers de Bordeaux, $171 \mathrm{p}$.

Denis, J. and Michard, G. (1983) Dissolution d'une solution solide : étude théorique et expérimentale. Bull. Minéral., 106, 309-319.

Fritz, B. (1975) Etude thermodynamique et simulation des réactions entre minéraux et solutions. Application à la géochimie des altérations et des eaux continentales. Sciences géologiques, Strasbourg, 41, 153 p.

Fritz, B. (1981) Etude thermodynamique et modélisation des réactions hydrothermales et diagénétiques. Sciences géologiques, Strasbourg, 65, $197 \mathrm{p}$.

Garrels, R.M. and Christ, C.L. (1965) Solutions, minerals and equilibria. Harper and Row, London.

Glynn, P.D. (1990) Modeling solid-solution aqueous-solution reactions in low-temperature aqueous systems. In Chemical modeling of aqueous systems II (Chapter 6), Bassett, R.L. and MELCHIOR, D. (eds.), Washington D.C., American Chemical Society Symposium Series, 416, 74-86. 
Glynn, P.D. and Reardon, E.J. (1990) Solid-solution aqueoussolution equilibria: Thermodynamic theory and representation. American Journal of Science, 290, 164-201.

Guy, B. (2003) Use of chemical potential phase diagrams to discuss aqueous saturation and precipitation/dissolution kinetics of solid solutions. Abstract volume of the international conference "Gas-water rock interactions induced by reservoir exploitation, $\mathrm{CO}_{2}$ sequestration, and other geological storage" held at I.F.P., Rueil-Malmaison, France (18-20 November).

Helgeson, H.C. (1969) Thermodynamics of hydrothermal systems at elevated temperature and pressures. Am. Journal Sci., 267, 724804.

Kervevan, C., Azaroual, M. and Durst, P. (2005) Improvement of the calculation accuracy of acid gas solubility in deep reservoir brines: application to the geological storage of $\mathrm{CO}_{2}$. Oil \& Gas Science and Technology - Rev. IFP, this issue.

Le Gallo, Y., Bildstein, O. and Brosse, E. (1998) Coupled reactionflow modeling of diagenetic changes in reservoir permeability, porosity and mineral compositions. Journal of Hydrology, 209, 366-388.

Lichtner, P. (1996) Continuum-formulation of multicomponentmultiphase reactive transport in porous media. In: Reactive transport in porous media, P.C. Lichtner, C.I. Steefel, E.H. Oelkers (Eds), Mineralogical Society of America, Reviews in Mineralogy, 34, 1-81.

Lietzke, M.H. and Stoughton, R.W. (1961) The calculation of activity coefficients from osmotic coefficients data. Jour. Chem. Phys., 65, 508-509.

Lippmann, F. (1977) The solubility products of complex minerals, mixed crystals, and three-layer clay minerals. $N$. Jb. Miner. Abh., 130, 243-263.

Lippmann, F. (1980) Phase diagrams depicting aqueous solubility of binary mineral systems. N. Jb. Miner. Abh., 139, 1-25.

Lippmann, F. (1982) Stable and metastable solubility diagrams for the system $\mathrm{CaCO}_{3}-\mathrm{MgCO}_{3}-\mathrm{H}_{2} \mathrm{O}$ at ordinary temperature. Bull. Minéral., 105, 273-279.

Made, B. (1994) Empirical relations to estimate kinetic constants of silicates dissolution from crystallographic and energetic parameters. Mineralogical Magazine, V.M. Goldschmidt Conference, 58A, 547-548.

Michard, G. (1986) Dissolution d'une solution solide : compléments et corrections. Bull. Minéral., 109, 239-251.

Michard, G. (1989) Équilibres chimiques dans les eaux naturelles. Editions Publisud, 358 p.
Michau, N. (1997) Modélisation cinétique de la formation des argiles en fonction de leur composition et de leur morphologie. Application à la diagenèse des grès de la Mer du Nord. PHD Thesis, Université Louis Pasteur de Strasbourg, 184 p.

Nourtier-Mazauric, E. (2003) Modélisation géochimique et numérique des interactions entre des solutions solides et une solution aqueuse - Extension du logiciel de réaction-transport ARCHIMEDE et application à la diagenèse minérale des réservoirs. $P H D$ Thesis, Université Jean Monnet et École Nationale Supérieure des Mines de Saint-Etienne, 203 p.

Pina, C.M., Enders, M. and Putnis, A. (2000) The composition of solid solutions crystallising from aqueous solutions: the influence of supersaturation and growth mechanisms. Chemical Geology, 168, 195-210.

Steefel, C.I. and van Cappellen, P. (1990) A new kinetic approach to modeling water-rock interaction: the role of nucleation, precursors, and Ostwald ripening. Geochim. Cosmochim. Acta, 54, 2657-2677.

Tardy, Y. and Fritz, B. (1981) An ideal solid solution model for calculating solubility of clay minerals. Clay minerals, 16, 361-373.

Tardy, Y. and Garrels, R. M. (1974) A method of estimating the Gibbs energies of formation of layer silicates. Geochimica et Cosmochimica Acta, 38, 1101-1116.

Thorstenson, D.C. and Plummer, L.N. (1977) Equilibrium criteria for two component solids reacting with fixed composition in aqueous phase. Example: the magnesian calcites. Am. J. Sci., 277, 1203-1223

Westall, J.C., Zachary, J.L. and Morel, F.M.M. (1976) MINEQL, a computer program for the calculation of chemical equilibrium composition of aqueous systems. Technical Note 18, Dept. Civil Eng., M.I.T., Cambridge, MA., 91 p.

Woods, T.L. and Garrels, R.M. (1992) Calculated solution-solid relations in the low temperature system $\mathrm{CaO}-\mathrm{MgO}-\mathrm{FeO}-\mathrm{CO}_{2}-\mathrm{H}_{2} \mathrm{O}$. Geochemica et Cosmochimica Acta, 56, 3031-3043.

Xu, T., Apps, J.A. and Pruess, K. (2004) Numerical simulation of $\mathrm{CO}_{2}$ disposal by mineral trapping in deep aquifers. Applied Geochemistry, 19, 917-936.

Yeh, G.T. and Tripathi, V.S. (1989) A critical evaluation of recent developments in hydrogeochemical transport models of reactive multichemical components. Water Resources Research, 25, 1, 93 108.

Final manuscript received in December 2004 